\title{
Contribution of anthropogenic land cover change emissions to pre-industrial atmospheric $\mathrm{CO}_{2}$
}

\author{
By CHRISTIAN H. REICK ${ }^{1 *}$, THOMAS RADDATZ ${ }^{1}$, JULIA PONGRATZ ${ }^{2}$ \\ and M A RTIN CLAU S SEN ${ }^{1,3},{ }^{1}$ Max Planck Institute for Meteorology, Bundesstr. 53, D-20146, Hamburg, \\ Germany; ${ }^{2}$ Department of Global Ecology, Carnegie Institution, Stanford, USA $;{ }^{3}$ KlimaCampus, University of \\ Hamburg, Germany
}

(Manuscript received 15 November 2009; in final form 11 June 2010)

\begin{abstract}
Based on a recent reconstruction of anthropogenic land cover change (ALCC), we derive the associated $\mathrm{CO}_{2}$ emissions since $800 \mathrm{AD}$ by two independent methods: a bookkeeping approach and a process model. The results are compared with the pre-industrial development of atmospheric $\mathrm{CO}_{2}$ known from antarctic ice cores. Our results show that pre-industrial $\mathrm{CO}_{2}$ emissions from ALCC have been relevant for the pre-industrial carbon cycle, although before $1750 \mathrm{AD}$ their trace in atmospheric $\mathrm{CO}_{2}$ is obscured by other processes of similar magnitude. After $1750 \mathrm{AD}$, the situation is different: the steep increase in atmospheric $\mathrm{CO}_{2}$ until $1850 \mathrm{AD}$ - this is before fossil fuel emissions rose to significant values-is to a substantial part explained by growing emissions from ALCC.
\end{abstract}

\section{Introduction}

Our current knowledge on the pre-industrial carbon cycle stems so far mostly from interpretation of ancient $\mathrm{CO}_{2}$ and its isotopes found in air bubbles of antarctic ice cores. In this study, we further constrain pre-industrial carbon fluxes by adding information from a recent reconstruction of the agricultural expansion since 800 AD (Pongratz et al., 2008a,b). We use this reconstruction to derive estimates of pre-industrial $\mathrm{CO}_{2}$ emissions from anthropogenic land cover change (ALCC).

Globally, emissions from ALCC cannot be obtained from measurements, but estimated only indirectly by using models (Ito et al., 2008). This is complicated by our incomplete knowledge on the modifications the biogeochemical cycling undergoes, when properties of vegetation and soils are changed by human activities like stubbing, ploughing, burning etc. (Ramankutty et al., 2007). Moreover, practices of land use change may differ widely, for example in terms of handling of remnants from tree cuttings. This explains why $\mathrm{CO}_{2}$ emissions from ALCC are a major uncertainty in todays global carbon cycle (p. 518 Solomon et al., 2007).

Accordingly, different approaches, relying on different information for the agricultural development, have been developed to calculate ALCC emissions. For times after 1850, Houghton has published various emission estimates derived from a book-

\footnotetext{
* Corresponding author.

e-mail: Christian.Reick@zmaw.de

DOI: 10.1111/j.1600-0889.2010.00479.x
}

keeping model (Houghton et al., 1983; Houghton and Hackler, 1995; Houghton, 1999, 2003, 2008). In this approach, deforestation statistics from official sources (FAO) are combined with estimates on vegetation and soil carbon content. A similar approach was invoked by de Campos et al. (2005), but they apply the HYDE land use database (Klein-Goldewijk, 2001) to follow the historical development of changes in cropland and pasture since 1700 AD. Also models with explicit representation of the biospheric processes have been employed: DeFries et al. (1999) applied the CASA model to land cover changes as obtained by a comparison of a satellite derived map of today's distribution of agricultural areas with two maps of potential vegetation, thus estimating the total carbon loss since the beginning of agriculture, but without temporal evolution; Levy et al. (2004) used the Hybrid global biosphere model and the cropland reconstruction since 1700 AD by Ramankutty and Foley (1999); and Strassmann et al. (2008) employed the Bern carbon cycle-climate model using the HYDE reconstruction (Klein-Goldewijk, 2001).

The studies mentioned so far could not tackle times before $1700 \mathrm{AD}$ because of lacking historical data on the actual extension of farmlands. To overcome this problem, Olofsson and Hickler (2008) tried to relate the archaelogically known developmental state of past societies since the Neolithic Revolution to farming intensity and derived in this way $\mathrm{CO}_{2}$ emissions from ALCC for seven time slices. For the last Millennium, the transient evolution of ALCC was recently followed in simulations with a coupled climate-carbon cycle model by Pongratz et al. (2009b) using the high detail land cover reconstruction from 
Pongratz et al. (2008a,b). Here not only emissions from ALCC were calculated, but also the re-uptake of carbon by land vegetation could be quantified.

In this study, we also use the landcover reconstruction by Pongratz et al. (2008a,b). This was derived by invoking data on the development of worldwide population during the last millennium. With these data, already existing high- resolution reconstructions of the last $300 \mathrm{yr}$ (Ramankutty and Foley, 1999; Klein-Goldewijk, 2001) were extended back to 800 AD by assuming local proportionality between population density and cropland extent. The soundness of this data set arises mainly from the fact that for this period farming area per capita and also population is fairly well known from historical documents like tithe reportings, tax rolls, parish registers or census reports. The extension of farming lands was then combined with a map for potential vegetation developed by Ramankutty and Foley (1999). It is clear that in this way only the major aspects of land cover change are captured, which is mainly deforestation. Nevertheless, in terms of $\mathrm{CO}_{2}$ emissions this is the most important type of land cover change, because of the pronounced contrast in carbon content between forests and croplands or pastures. Emission estimates were shown to be stable with respect to uncertainties in the reconstruction arising, for example from uncertainties in population estimates and agrotechnical improvements (Pongratz et al., 2009b).

Using the above-mentioned land cover reconstruction, $\mathrm{CO}_{2}$ emissions from agricultural expansion are derived in this study by two different approaches, using a bookkeeping ansatz and a process based model. Because these two approaches employ completely different process descriptions, have no common parameters, and have been developed independently without any tuning to obtain comparable results, they give, except for using the same land cover reconstruction, independent estimates of emissions from ALCC. The process model was already used in Pongratz et al. (2009b) to derive emission estimates for ALCC (although in a completely different simulation setup). In this study, the next step is taken by using the emission estimates to infer their contributions to the variability of atmospheric $\mathrm{CO}_{2}$ during the last Millennium as observed in icecores.

\section{Emissions from anthropogenic land cover change}

The first of the two approaches to derive emissions from ALCC is based on the bookkeeping ansatz by Houghton (Houghton et al., 1983; Houghton and Hackler, 1995; Houghton, 1999, 2003). Here, empirical emission factors for different land cover changes (e.g. from forests to croplands, or pastures to croplands) and different climatic zones (tropical, temperate, boreal) are used to obtain the $\mathrm{CO}_{2}$ release to the atmosphere. In this study, we combined the original bookkeeping model with a Monte Carlo approach to deal also with parameter uncertainties (for details, see Appendix S1).
The bookkeeping approach ignores changes in atmospheric $\mathrm{CO}_{2}$ and climate together with accompanying modifications in the cycling of terrestrial carbon. Such complications are accounted for by our second approach, invoking the process-based model JSBACH of the terrestrial biosphere (Raddatz et al., 2007) which has been implemented into the model of global atmospheric circulation ECHAM5 (Roeckner et al., 2005). Process models, such as JSBACH, describe the cycling of carbon from its uptake by plants to its release back to the atmosphere via the soils by using detailed descriptions of all intermediate processes such as photosynthesis, annual cycle of growth and shedding of leaves and heterotrophic soil respiration. All those processes depend on the prevailing climatic conditions such as plant available radiation, temperature, soil hydrology and atmospheric $\mathrm{CO}_{2}$ concentration. In the study of ALCC by Pongratz et al. (2009b), JSBACH was run as part of a comprehensive Earth system model, with fully coupled carbon cycle dynamics throughout land, ocean and atmosphere components. In contrast, in the present study JSBACH is run at higher spatial resolution $\left(\approx 2^{\circ} \times 2^{\circ}\right)$ to achieve a more accurate representation of carbon fluxes, although in a simplified setup: we ran the land component JSBACH separately from other model components by driving it offline with climatic boundary conditions that were pre-computed from two 18-yr climate simulations with the coupled ECHAM5-JSBACH model, one (pre-industrial) at a $\mathrm{CO}_{2}$ concentration of $278 \mathrm{ppm}$, the other for more recent conditions at $369 \mathrm{ppm}$. From those two time slices, the climate conditions for the whole time span 800-1992 AD were generated by interpolation and scaling with observed $\mathrm{CO}_{2}$ (for more details, see Appendix S2).

For the time since 1850, Fig. 1(a) depicts our results together with the most recent estimates of ALCC emissions by Houghton (2008), which are consistent with those from other studies (Denman et al., 2007). Both our models give values within the uncertainty of Houghton's, which is considered to be $0.5 \mathrm{GtC} \mathrm{yr}^{-1}$ (Canadell et al., 2007) or about $\pm 50 \%$ according to (Ramankutty et al., 2007). With our bookkeeping model, we find a similar range of uncertainty (the shaded range in Fig. 1). These uncertainties are estimated by a random variation of parameters within reasonable limits (see Appendix S1). Cumulated emissions from 1850 to $1990 \mathrm{AD}$ match the range of published estimates (Table 1). The pronounced emission peak in Fig. 1(a) around 1955 AD produced by our models, which is not seen in Houghton's estimates, can be traced back to significant differences in deforestation rates underlying the reconstructions of ALCC after 1960 AD; this was thoroughly analysed by Jain and Yang (2005) and this difference is also seen in the study by Bondeau et al. (2007).

With only one exception around $1400 \mathrm{AD}$, the emissions obtained from our process model are less than those from the bookkeeping model (see Fig. 1 and Table 1). As demonstrated in Fig. 2, this difference can be fully attributed to the different handling of soil carbon following ALCC: with respect to the loss 

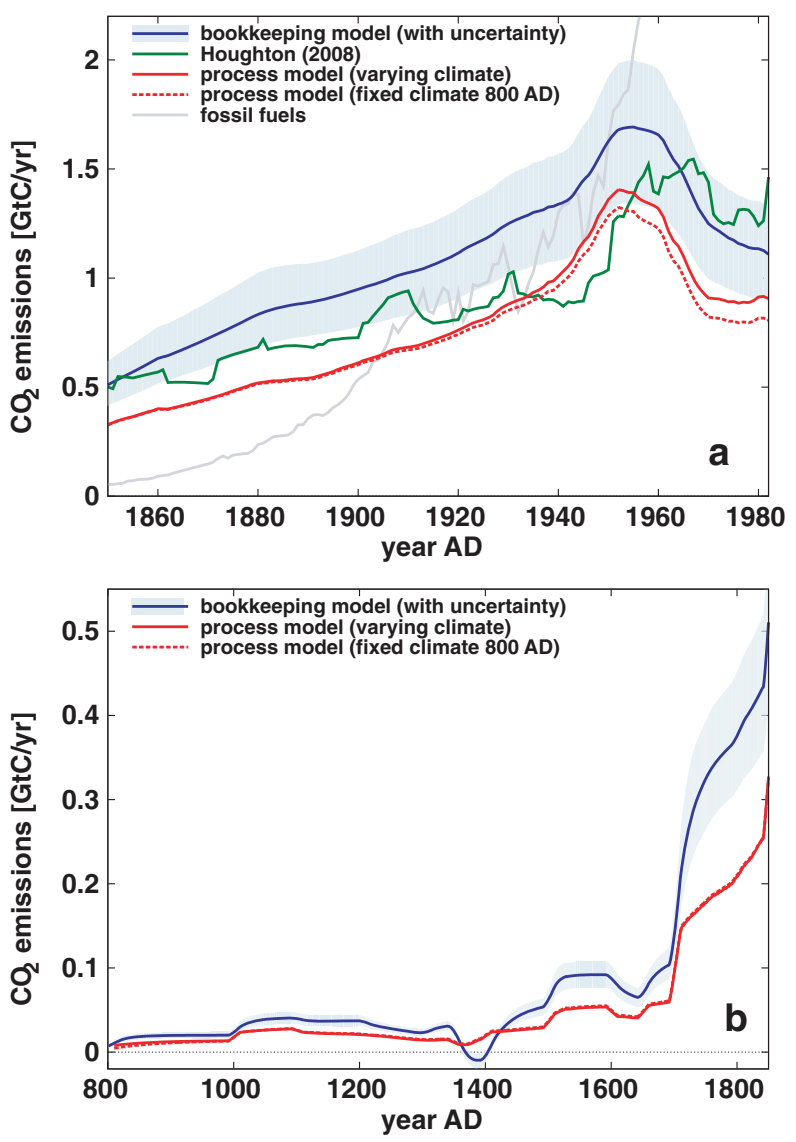

Fig. 1. Emissions from anthropogenic land cover change. (a)

Comparison of our results with those published by Houghton (2008). For comparison also the emissions from fossil fuels (Marland et al., 2008) are plotted. (b) Our results for 800-1850 AD. - Emissions from ALCC have been subjected to an $18 \mathrm{yr}$ running mean.

of vegetation carbon, the two models agree very well, although the modelling approaches are very different-prescribed carbon densities in the bookkeeping model versus a detailed description of carbon turnover from photosynthesis to litter production in the process model. But with respect to the soil compartment differences in model structure turn out to be relevant: For the process model, ALCC leads to a gain in soil carbon throughout most of the centuries, whereas in the bookkeeping model soil carbon is typically lost, with only one major exception around 1950 where deforestation rates peaked. One important difference between the two modelling approaches with respect to soils concerns the management of agricultural lands. The emission factors used for ALCC in the bookkeeping model are based on observed carbon losses after land conversions (Guo and Gifford, 2002). These emission factors include losses of soil carbon arising from the management of agricultural lands after conversion (ploughing, weeding, etc.) which typically increase soil erosion. Such carbon losses are not accounted for in our process model. Nevertheless, in view of the long time span considered here, it is not immediately obvious which of the two approaches is more appropriate: One can argue that carbon losses from management have been less than today during the last centuries because, with industrialization, cultivation was significantly intensified by the use of fuel-driven machines so that for today the process model arguably underestimates emissions. By contrast, the bookkeeping model should overestimate emissions for times before the industrial revolution.

To analyse the importance of climate for the emissions from ALCC, we performed an additional simulation with the process model using fixed pre-industrial climate input. The result is also shown in Fig. 1 (dotted). For times before 1900, emission values are almost indistinguishable, only afterwards the two curves separate, but their difference is much smaller than the overall uncertainty of the emission estimates. This minor influence of climate on the emissions can be explained by noting that ALCC emissions from deforestation are mostly determined by the wood biomass cleared, and depend to a smaller extent also on the contrast in NPP (net primary productivity) between the forest cleared and the agricultural fields replacing them. But neither the wood density nor the NPP contrast can have changed substantially between pre-industrial times and today because the differences in climate are still too small to affect wood density of forests, and the possible changes in NPP due to $\mathrm{CO}_{2}$ fertilization drop out in the NPP contrast. The small differences seen after 1900 are the result of an additional effect, namely the faster soil remineralization from the increasing temperatures in the simulation with climate change.

\section{ALCC emissions and atmospheric $\mathrm{CO}_{2}$}

Commonly anthropogenic climate change is associated with the industrial revolution (Solomon et al., 2007 p. 138). But only after 1950 industrial $\mathrm{CO}_{2}$ emissions from fossil fuel burning and cement production grew significantly larger than those accompanying agricultural expansion (Fig. 1a). This naturally leads to the question since when mankind started to impact on carbon cycle and climate (Ruddiman, 2003; Ruddiman, 2007).

In Fig. 3(a), published data on atmospheric $\mathrm{CO}_{2}$ from ice cores are combined by accounting for measurement and dating uncertainties. From the resulting 'certainty' map it is obvious that three distinct phases can be distinguished: the increase by $4 \mathrm{ppm}$ between $1000 \mathrm{AD}$ and $1100 \mathrm{AD}$, the decrease by about 5 ppm during the following $600 \mathrm{yr}$, and the steep increase after $1750 \mathrm{AD}$ continuing until today. The long-lasting negative trend in atmospheric $\mathrm{CO}_{2}$ during the centuries before $1700 \mathrm{AD}$ roughly coincides with a period of globally decreasing temperatures (compare Fig. 3b), eventually leading to the so-called Little Ice Age, so that one might argue that $\mathrm{CO}_{2}$ simply follows temperatures. But the situation cannot be that simple: First of all, the Medieval Warm Period around 1050 AD does not coincide with the period of high $\mathrm{CO}_{2}$ values between 1100 and $1250 \mathrm{AD}$. And secondly, although the start of the steep increase in $\mathrm{CO}_{2}$ 
Table 1. Cumulated carbon exchanges for different periods (in $\mathrm{GtC}$ )

\begin{tabular}{|c|c|c|c|c|c|}
\hline Years AD & $1100-1700$ & $1500-1750$ & $1700-1850$ & $1850-1990$ & $1700-1990$ \\
\hline Atmospheric uptake $^{\mathrm{a}}$ (median from Fig. 3a) & -11 & -9 & 20 & 140 & 160 \\
\hline Fossil fuel emission (Marland et al., 2008) & 0 & 0 & 1 & 219 & 220 \\
\hline ALCC emission (This study: bookkeeping model) & 29 & 30 & 51 & 153 & 204 \\
\hline ALCC emission (This study: process model) & 18 & 18 & 29 & 110 & 139 \\
\hline ALCC emission (Pongratz et al., 2009b) & 19 & 19 & 30 & 98 & 128 \\
\hline ALCC emission (Houghton, 2008) & - & - & - & 133 & - \\
\hline ALCC emission (DeFries et al., 1999) & - & - & - & $125-151$ & - \\
\hline ALCC emission (Strassmann et al., 2008) & - & - & - & - & 177 \\
\hline ALCC emission (Levy et al., 2004 ) & - & - & 49 & 173 & 222 \\
\hline ALCC emission (de Campos et al., 2005 ${ }^{\mathrm{b}}$ ) & - & - & 45 & 94 & 139 \\
\hline ALCC emission (Olofsson and Hickler, 2008) & - & - & 41 & 148 & 189 \\
\hline Ocean release (from Law Dome) & - & $29^{\mathrm{c}}$ & $-9^{\mathrm{d}}$ & - & - \\
\hline Land release (from Law Dome) & - & $-37^{\mathrm{c}}$ & $30^{\mathrm{d}}$ & - & - \\
\hline
\end{tabular}

${ }^{a}$ We use $1 \operatorname{ppmv}\left(\mathrm{CO}_{2}\right)=2.123 \mathrm{GtC}$.

${ }^{\mathrm{b}}$ Graphically from Fig. 3 therein.

${ }^{c}$ From Joos et al. (1999).

${ }^{\mathrm{d}}$ Graphically estimated from Fig. 7c in Trudinger et al. (2002).
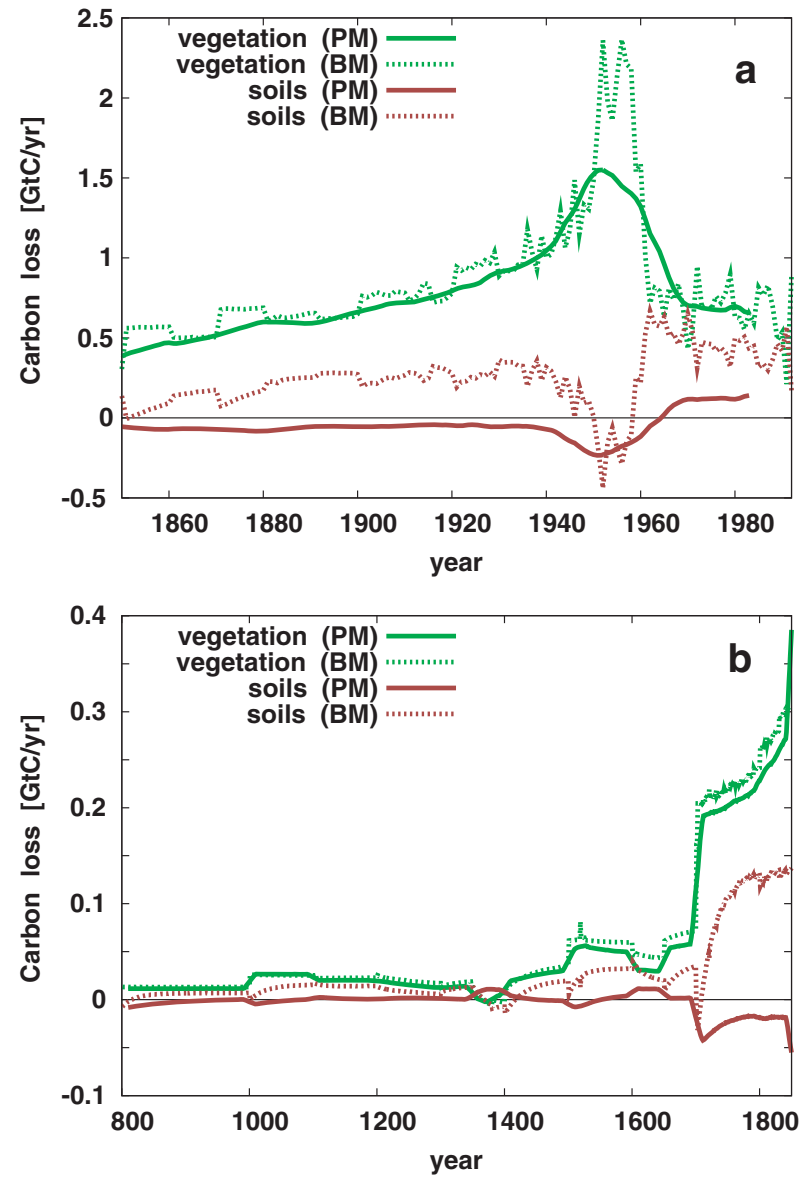

Fig. 2. Comparison of changes in soil and vegetation carbon following ALCC in the bookkeeping model (BM) and the process model (PM). after $1750 \mathrm{AD}$ could possibly be understood as a lagged reaction to a small rise in temperatures after $1700 \mathrm{AD}$, the steady increase in $\mathrm{CO}_{2}$ concentrations that continued uneffectedly even after the cooling following the Tambora eruption in 1815 AD (Fig. 3), render temperature as single cause for the pre-industrial development of $\mathrm{CO}_{2}$ questionable. Although temperature changes may explain part of the observed changes, the natural fluctuations in the global carbon cycle, whose size is essentially unknown, may also play a considerable role on the timescale of centuries considered here. In fact, as the age of ocean water masses can be several thousand years (Sikes et al., 2000) and the highly biologically active continental shelves are strongly altered by glacial cycles via the associated sea level changes, the ocean carbon may always be in a state of disequilibrium causing varying $\mathrm{CO}_{2}$ exchange fluxes with the atmosphere.

Nevertheless, the negative trend in atmospheric $\mathrm{CO}_{2}$ before $1700 \mathrm{AD}$ can probably be attributed to a land carbon sink: The deconvolution studies by Joos et al. (1999) and Trudinger et al. (2002), which employ besides $\mathrm{CO}_{2}$ also isotopic records of $\delta^{13} \mathrm{CO}_{2}$ from Law Dome ice cores, both suggest a land carbon sink and an ocean source between 1500 and 1750 AD. Using a simple carbon model, the authors explain this by a slowing down of soil turnover (Trudinger et al., 1999, 2005) caused by decreasing temperatures during this time. Our study reveals that during this period emissions from ALCC have been of similar magnitude as the decrease in atmospheric $\mathrm{CO}_{2}$, and also of magnitude comparable to estimated ocean emissions (Table 1). Accordingly, emissions from ALCC must have had an influence on atmospheric $\mathrm{CO}_{2}$ concentrations. This holds also true for the longer period 1100-1700 AD. With the assumption that only $20 \%$ of the $18-29$ GtC emissions from ALCC had stayed 
Fig. 3. Comparison of atmospheric $\mathrm{CO}_{2}$ obtained from antarctic icecores (a) with reconstructions of Northern Hemisphere temperature anomaly with respect to average 1500-1899 AD (b) for 800-1850 AD. Data for (a) are from Law Dome (Etheridge et al., 1996, 2001; Levchenko et al., 1996, 1997; Meure et al., 2006), EPICA Dome C (Monnin et al., 2004a,b), Dronning Maud Land and South Pole (Siegenthaler, 2005; Siegenthaler et al., 2005). The grey scale shows the 'certainty' of $\mathrm{CO}_{2}$ values (for details see Appendix S3). Data for (b) are from Osborn and Briffa (2007). Grey shading shows the percentage of overlap between the different temperature reconstructions.

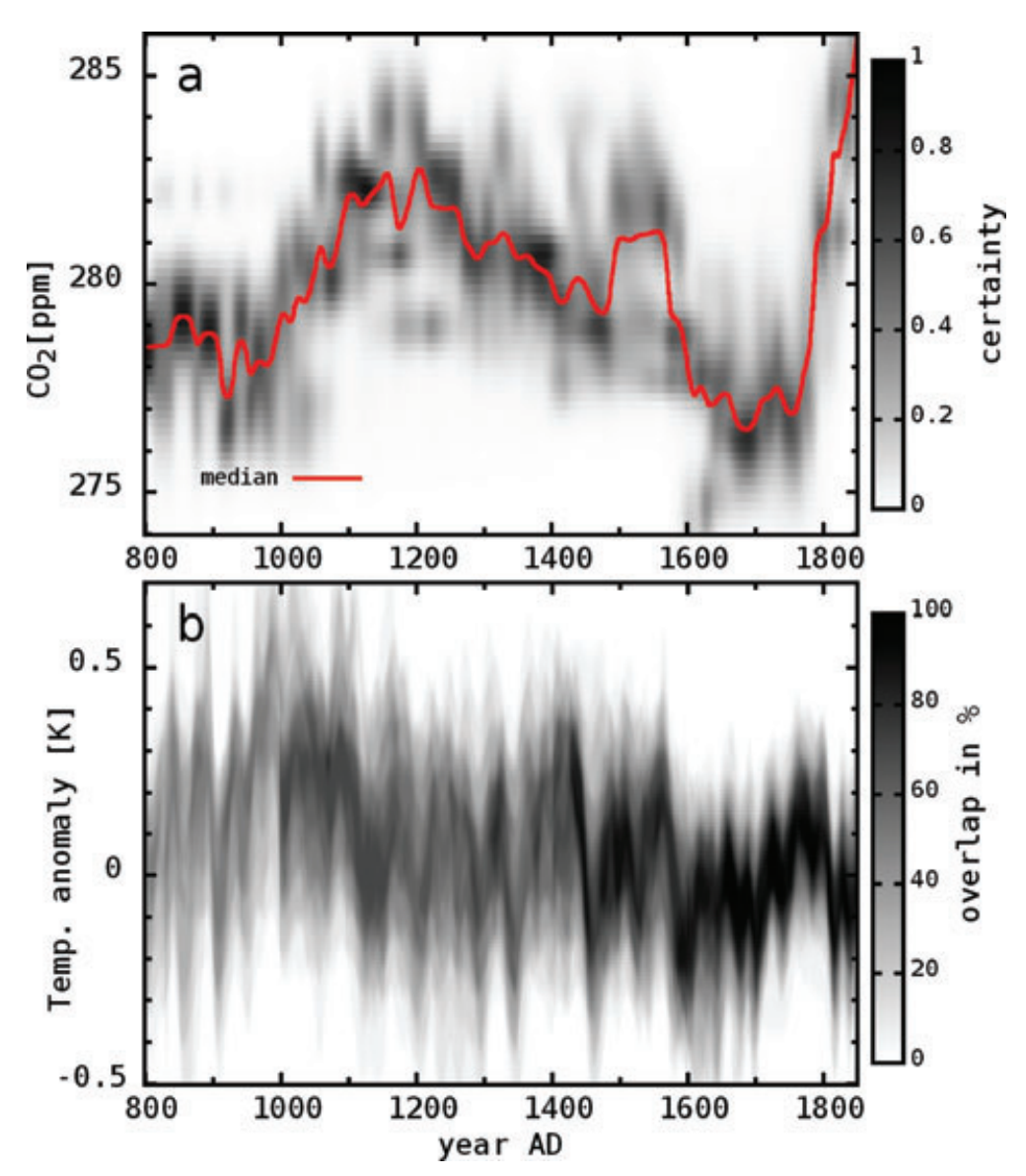

in the atmosphere (today: $40 \%$ House et al., 2002; Pongratz et al., $2009 \mathrm{~b}$ estimate $21 \%$ for the period $800-1850$ AD), atmospheric $\mathrm{CO}_{2}$ would have decreased 1.7-2.7 ppm less than without ALCC, according to the emission estimates from the process and bookkeeping model. The natural downward trend between 1100 and $1700 \mathrm{AD}$ therefore must have been stronger than the observed 5 ppm decrease, namely about 7 ppm when accounting for the contributions from ALCC to observed $\mathrm{CO}_{2}$. Accordingly, emissions from ALCC started to modify atmospheric $\mathrm{CO}_{2}$ during late medieval times, but could not reverse the natural trend. Therefore, the remarkable trend reversal observed in atmospheric $\mathrm{CO}_{2}$ during the 12th century, that marked the end of a long-lasting increase by $20 \mathrm{ppm}$ during the previous 7000 yr (Indermühle et al., 1999), can, according to our study, not be related to human activities.

Between 1700 and $1850 \mathrm{AD}$ the atmospheric carbon pool increased by about $20 \mathrm{GtC}$ (Table 1). Emissions from fossil fuel combustion during this time, totally less than $1.5 \mathrm{GtC}$ until 1850 (Marland et al., 2008), are too small to have caused this increase. This was already recognized during the mid-1980s when first $\delta^{13} \mathrm{C}$ records from treerings became available (Emanuel et al., 1984), and was later on substantiated by the first $\mathrm{CO}_{2}$ measurements from antarctic ice cores (Neftel et al., 1985; Siegenthaler and Oeschger, 1987; Kammen and Marino, 1993). Already in these early studies emissions from ALCC have been proposed as explanation. But only after the SAGE (Ramankutty and Foley, 1999) and HYDE (Klein-Goldewijk, 2001) data sets on historical changes in agricultural lands back to $1700 \mathrm{AD}$ were published, direct estimates of emissions from ALCC became possible. These range between 41 and 49 GtC cumulated emissions between 1700 and $1850 \mathrm{AD}$ (Table 1), whereas in this study we find in close agreement with Pongratz et al. (2009b) $29 \mathrm{GtC}$ from the process model, and about $51 \mathrm{GtC}$ from the bookkeeping approach (Table 1). The double deconvolution studies on Law Dome ice core data (Joos et al., 1999; Trudinger et al., 2002) indicate that the ocean has been a carbon sink during this period. The increase in atmospheric $\mathrm{CO}_{2}$ is therefore driven completely by land emissions. Making once more the conservative assumption that only $20 \%$ of the emissions from ALCC remain airborne, at least $3 \mathrm{ppm}$ (in case of the process model) to $5 \mathrm{ppm}$ (for our bookkeeping and all other published models) of the 8 ppm increase between 1700 and 1850 AD must be caused by ALCC.

\section{Discussion}

Much debated is the hypothesis by Ruddiman (2003) that the rise in atmospheric $\mathrm{CO}_{2}$ and methane concentrations after 8000 and 
$5000 \mathrm{BP}$, respectively, found in antarctic ice cores are the traces of human deforestation and early rice cultivation that prevented us from entering the next glacial cycle (Ruddiman, 2007). But in view of the many difficulties encountered to reach firm ground for times that long ago, it seems much more straightforward to tackle the question of global human impacts for historical times first.

For the time between 1100 and $1700 \mathrm{AD}$, the ice core records show a long-lasting decrease in atmospheric $\mathrm{CO}_{2}$. This is an indication that other processes than ALCC must have dominated the $\mathrm{CO}_{2}$ exchange between land and atmosphere. Especially, the long-lasting Northern Hemisphere cooling leading to the Little Ice Age could have slowed down soil respiration (Trudinger et al., 1999, 2005) causing atmospheric $\mathrm{CO}_{2}$ to decrease significantly. The origin of this cooling is still under debate (Mann, 2007; Wanner et al., 2008). The different hypotheses also include a possible role of albedo increase following ALCC (Brovkin et al., 1999; Govindasamy et al., 2001; Goosse et al., 2006). But this could not be supported in a more recent study by Pongratz et al. (2009a) using the same high detail ALCC reconstruction underlying also the present investigation. Finally, the centurylong increase in atmospheric $\mathrm{CO}_{2}$ before $1100 \mathrm{AD}$ can according to our study also not be the result of emissions from ALCCthe emission values obtained from the two types of models we invoke here, are too small.

From the values obtained in this study it is evident that before $1700 \mathrm{AD}$ the $\mathrm{CO}_{2}$ emissions from ALCC may have slightly reduced the decrease in atmospheric $\mathrm{CO}_{2}$ content. In the 18th century, the situation changed. Here, emissions from ALCC had grown to sizes that caused at least a substantial part of the rise in atmospheric $\mathrm{CO}_{2}$ observed after $1750 \mathrm{AD}$. This situation continued until the widespread use of fossil fuels led to emissions of comparable size during the early 20th century.

These results were obtained by employing two very different models, so that our conclusions are largely independent from the representation of the processes in the models. Nevertheless, certain processes are missing in both models, namely wood harvest and shifting cultivation have not been included because of lack of data. But we do not expect that a realistic inclusion of these processes could significantly alter our conclusions: Even today, under conditions of still increasing exploitation of forests, carbon losses by harvest are largely compensated by regrowth (Houghton, 2003). And shifting cultivation may locally cause substantial emissions, but these are compensated by regrowth on the abandoned areas of the same rotational system, in particular with the long fallow period that is assumed for the preindustrial era (Olofsson and Hickler, 2008). Furthermore, soil carbon losses associated with shifting cultivation are smaller than for permanent agriculture (Houghton and Goodale, 2004). For these reasons, the net emissions influencing atmospheric $\mathrm{CO}_{2}$ are likely not substantially underestimated by omitting these processes.
Additional uncertainties arise from the underlying reconstruction of ALCC. Along with the particular reconstruction used here, Pongratz et al. (2008b) also provided lower and upper estimates for the expansion of agricultural areas, which envelop the uncertainties associated with the reconstruction method. In Pongratz et al. (2009b), using the process model of this study in an Earth system setup, it was shown that with the upper estimate pre-industrial emissions from ALCC are at most 15\% larger. Accounting for these additional $15 \%$ in the above calculations does not alter our conclusions for contributions of ALCC to pre-industrial atmospheric $\mathrm{CO}_{2}$. Our conclusion of an only subordinate human impact on atmospheric $\mathrm{CO}_{2}$ prior to 1750 would be even more robust, when for the reconstructions a strong nonlinear dependence of land use per capita on population density is assumed, as proposed by Mather et al. (1999) and recently used in reconstructions of ALCC for Europe by Kaplan et al. (2009). Under such assumptions emissions from ALCC would likely be shifted to earlier millennia than obtained from the reconstruction by Pongratz et al. (2008b), so that for the period studied here less emissions from ALCC are expected. At the same time, this would leave an even larger part of the $\mathrm{CO}_{2}$ increase after 1750 unexplained.

\section{References}

Bondeau, A., Smith, P., Zaehle, S., Schaphoff, S., Lucht, W. and coauthors. 2007. Modelling the role of agriculture for the 20th century global terrestrial carbon balance. Global Change Biol. 13, 679-706, doi:10.1111/j.1365-2486.2006.01305.x.

Brovkin, V., Ganopolski, A., Claussen, M., Kubatzki, C. and Petoukhov, V. 1999. Modelling climate response to historical land cover change. Global Ecol. Biogeogr. 8, 509-517.

Canadell, J., LeQuéré, C., Raupach, M., Field, C., Buitenhuis, E. and coauthors. 2007. Contributions to accelerating atmospheric $\mathrm{CO}_{2}$ growth from economic activity, carbon intensity, and efficiency of natural sinks. PNAS 104, 18866-18870.

de Campos, C. P., Muylaert, M. S. and Rosa, L. P. 2005. Historical $\mathrm{CO}_{2}$ emission and concentrations due to land use change of croplands and pastures by country. Sci. Total Environ. 346, 149-155.

DeFries, R., Field, C., Fung, I., Collatz, G. and Bounoua, L. 1999. Combining satellite data and biogeochemical models to estimate global effects of human-induced land cover change on carbon emissions and primary productivity. Global Biogeochem. Cycles 13, 803-815.

Denman, K., Brasseur, G., Chidthaisong, A., Ciais, P., Cox, P. and coauthors. 2007. Couplings between changes in the climate system and biogeochemistry. In: Climate Change 2007: The Physical Science Basis. Contribution of Working Group I to the Fourth Assessment Report of the Intergovernmental Panel on Climate Change, (eds. S. Solomon, D. Qin, M. Manning, Z. Chen, M. Marquis, K. Averyt, M. Tignor and H. Miller), Cambridge University Press, Cambridge, UK and New York, NY, USA.

Emanuel, W., Killough, G., Post, W. and Shugart, H. 1984. Modeling terrestrial ecosystems in the global carbon cycle with shifts in carbon storage capacity by land-use change. Ecology 65, 970-983.

Etheridge, D., Steele, L., Langenfelds, R., Francey, R., Barnola, J.M. and co-authors. 1996. Natural and anthropogenic changes in 
atmospheric $\mathrm{CO}_{2}$ over the last 1000 years from air in antarctic ice and firn. J. Geophys. Res. 101, 4115-4128.

Etheridge, D., Steele, L., Langenfelds, R., Francey, R., Barnola, J.M. and co-authors. 2001. Law dome atmospheric $\mathrm{CO}_{2}$ data, Technical Report, IGBP PAGES/World Data Center for Paleoclimatology, NOAA/NGDC Paleoclimatology Program, Boulder CO, USA.

Goosse, H., Arzel, O., Luterbacher, J., Mann, M., Renssen, H. and coauthors. 2006. The origin of the European medieval warm period. Clim. Past 2, 99-113.

Govindasamy, B., Duffy, P. and Caldeira, K. 2001. Land use changes and northern hemisphere cooling. Geophys. Res. Lett. 28, 291294.

Guo, L. and Gifford, R. 2002. Soil carbon stocks and land use change: a meta analysis. Global Change Biol. 8, 345-360.

Houghton, R. 1999. The annual net flux of carbon to the atmosphere from changes in land use 1850-1990. Tellus B 51, 298-313.

Houghton, R. 2003. Revised estimates of the annual net flux of carbon to the atmosphere from changes in land use and land management. Tellus55B, 378-390.

Houghton, R. 2008. Carbon flux to the atmosphere from land-use changes: 1850-2005. In TRENDS: a compendium of data on global change, Technical Report, Carbon Dioxide Information Analysis Center, http://cdiac.ornl.gov, Oak Ridge National Laboratory, U.S. Department of Energy, Oak Ridge, TN, USA.

Houghton, R. and Goodale, C. 2004. Effects of land-use change on the carbon balance of terrestrial ecosystems. In: Ecosyst. Landuse Change (eds. R. Houghton, R. DeVries and G. Asner), Geophysical Monograph Series, Volume 153, AGU, Washington, DC.

Houghton, R. and Hackler, J. 1995. Continental scale estimates of the biotic carbon flux from land cover change: 1850-1980, Technical Report, Oak Ridge National Laboratory, Oak Ridge National Laboratory, Oak Ridge, TN.

Houghton, R., Hobbie, J., Melillo, J., Moore, B., Peterson, B. and coauthors. 1983. Changes in the carbon content of terrestrial biota and soils between 1860 and 1980: a net release of $\mathrm{CO}_{2}$ to the atmosphere. Ecol. Monogr. 53, 235-262.

House, J., Prentice, I. and LeQuéré, C. 2002. Maximum impacts of future reforestation or deforestation on atmospheric $\mathrm{CO}_{2}$. Global Change Biol. 8, 1047-1052.

Indermühle, A., Stocker, T., Joos, F., Fischer, H., Smith, H. and co-authors. 1999. Holocene carbon-cycle dynamics based on $\mathrm{CO}_{2}$ trapped in ice at Taylor Dome, Antarctica. Nature 398, 121126.

Ito, A., Penner, J., Prather, M., de Campos, C., Houghton, R. and coauthors. 2008. Can we reconcile differences in estimates of carbon fluxes from land-use change and forestry for the 1990s?. Atmos. Chem. Phys. 8, 3291-3310.

Jain, A. and Yang, X. 2005. Modeling the effects of two different land cover change data sets on the carbon stocks of plants and soils in concert with $\mathrm{CO}_{2}$ and climate change. Global Biogeochem. Cycles 19, GB2015, doi: 10.1029/2004GB002349.

Joos, F., Meyer, R., Bruno, M. and Leuenberger, M. 1999. The variability in the carbon sinks as reconstructed for the last 1000 years. Geophys. Res. Lett. 26, 1437-1440.

Kammen, D. and Marino, B. 1993. On the origin and magnitude of preindustrial anthropogenic $\mathrm{CO}_{2}$ and $\mathrm{CH}_{4}$ emissions. Chemosphere 26, 69-86.
Kaplan, J., Krumhardt, K. and Zimmermann, N. 2009. The prehistoric and preindustrial deforestation of Europe. Quater. Sci. Rev. 28, 3016-3034.

Klein-Goldewijk, K. 2001. Estimating global land use change over the past 300 years. Global Biogeochem. Cycles 15, 417-433.

Levchenko, V., Francey, R., Etheridge, D., Tuniz, C., Head, J. and coauthors. 1996. The 14C "bomb spike" determines the age spread and age of $\mathrm{CO}_{2}$ in law dome firm and ice. Geophys. Res. Lett. 23, 3345-3348.

Levchenko, V., Etheridge, D., Francey, R., Trudinger, C., Tuniz, C. and co-authors. 1997. Measurements of the ${ }^{14} \mathrm{CO}_{2}$ bomb pulse in firn and ice at Law Dome, Antarctica. Nucl. Instrum. Methods. Phys. Res. B123, 290-295.

Levy, P., Friend, A., White, A. and Cannell, M. 2004. The influence of land use change on global-scale fluxes of carbon from terrestrial ecosystems. Clim. Change 67, 185-209.

Mann, M. 2007. Climate over the past two millennia. Ann. Rev. Earth. Planet. Sci. 35, 111-136.

Marland, G., Andres, B. and Boden, T. 2008. Global $\mathrm{CO}_{2}$ emissions from fossil-fuel burning, cement manufacture, and gas flaring: 1751-2005., Technical Report, Carbon Dioxide Information Analysis Center. Available: http://cdiac.ornl.gov/ftp/ndp030/.

Mather, A., Fairbanks, J. and Needle, C. 1999. The course and drivers of forest transition: the case of France. J. Rural Stud. 15, 65-90.

Meure, C., Etheridge, D., Trudinger, C., Steele, P., Langenfelds and coauthors. 2006. Auxiliary material to: Law Dome $\mathrm{CO}_{2}, \mathrm{CH}_{4}$ and $\mathrm{N}_{2} \mathrm{O}$ ice core records extended to 2000 years BP. Geophys. Res. Lett. 33, L14810. doi:10.1029/2006GL02615.

Monnin, E., Steig, E., Siegenthaler, U., Kawamura, K., Schwander, J. and co-authors. 2004a. Evidence for substantial accumulation rate variability in Antarctica during the holocene through synchronization of $\mathrm{CO}_{2}$ in the Taylor Dome, Dome $\mathrm{C}$ and DML ice cores. Earth Planet. Sci. Lett. 224, 45-54. doi:10.1016/ j.eps1.2004.05.007.

Monnin, E., Steig, E., Siegenthaler, U., Kawamura, K., Schwander, J. and co-authors. 2004b. EPICA Dome C ice core high resolution holocene and transition $\mathrm{CO}_{2}$ data, Technical Report, IGBP PAGES/World Data Center for Paleoclimatology, OAA/NGDC Paleoclimatology Program, Boulder CO, USA.

Neftel, A., Moor, E., Oeschger, H. and Stauffer, B. 1985. Evidence from polar ice cores for the increase in atmospheric $\mathrm{CO}_{2}$ in the past two centuries. Nature 315, 45-47.

Olofsson, J. and Hickler, T. 2008. Effects of human land-use on the global carbon cycle during the last 6,000 years. Veget. Hist. Archaeobot. 17, 605-615.

Osborn, T. and Briffa, K. 2007. Fig. 6.13d in Denman et al. (2007). Data from www.cru.uea.ac.uk/timo/datapagesfilefig6.13_ ipccar4_wg1_2007.overlaps.txt.

Pongratz, J., Reick, C., Raddatz, T. and Claussen, M. 2008a. A global land cover reconstruction AD 800 to 1992 - Technical description, Reports on Earth System Science 51, Max Planck Institute for Meteorology, Hamburg, Germany.

Pongratz, J., Reick, C., Raddatz, T. and Claussen, M. 2008b. A reconstruction of global agricultural areas and land cover for the last millennium. Global Biogeochem. Cycles 22, GB3018. doi:10.1029/2007GB003153. 
Pongratz, J., Raddatz, T., Reick, C., Esch, M. and Claussen, M. 2009a. Radiative forcing from anthropogenic land cover change since 800 AD. Geophys. Res. Lett. 36, L02709.

Pongratz, J., Reick, C., Raddatz, T. and Claussen, M. 2009b. Effects of anthropogenic land cover change on the carbon cycle of the last millennium. Global Biogeochem. Cycles 23, GB4001. doi:10.1029/2009GB003488.

Raddatz, T., Reick, C., Knorr, W., Kattge, J., Roeckner, E. and coauthors. 2007. Will the tropical land biosphere dominate the climate carbon cycle feedback during the twenty-first century? Clim. Dynam. 29, 565-574.

Ramankutty, N. and Foley, J. 1999. Estimating historical changes in global land cover: Croplands from 1700 to 1992. Global Biogeochem. Cycles 13, 997-1027.

Ramankutty, N., Gibbs, H., Achard, F., DeFries, R., Foley, J. and coauthors. 2007. Challenges to estimating carbon emissions from tropical deforestation. Global Change Biol. 13, 51-66.

Roeckner, E., Brokopf, R., Esch, M., Giorgetta, M., Hagemann, S. and co-authors. 2005. Sensitivity of simulated climate to horizontal and vertical resolution in the ECHAM5 atmosphere model. J. Clim. 19, 3771-3791.

Ruddiman, W. 2003. The anthropogenic greenhouse era began thousands of years ago. Clim. Change 61, 261-293.

Ruddiman, W. 2007. The early anthropogenic hypothesis: challenges and responses. Rev. Geophys. 45, RG4001, doi:10.1029/2006RG000207.

Siegenthaler, U. 2005. EPICA Dronning Maud Land $\mathrm{CO}_{2}$ data for the last millennium, Data Contribution Series 2005-081, IGBP PAGES/World Data Center for Paleoclimatology, NOAA/ NCDC Paleoclimatology Program, Boulder CO, USA. Available via ftp://ftp.ncdc.noaa.gov/pub/data/paleo/icecore/antarctica/maud/ edml-co2-2005.txt.

Siegenthaler, U. and Oeschger, H. 1987. Biospheric $\mathrm{CO}_{2}$ emissions during the past 200 years reconstructed by deconvolution of ice core data. Tellus 39B, 140-154.

Siegenthaler, U., Monnin, E., Kawamura, K., Spahni, R., Schwander, J. and co-authors. 2005. Supporting evidence from the EPICA Dronning Maud Land ice core for atmospheric $\mathrm{CO}_{2}$ changes during the past millennium. Tellus 57B, 51-57. doi:10.1111/j.1600-0889.2005.00131.x.

Sikes, L., Samson, C., Guilderson, T. and Howard, W. 2000. Old radiocarbon ages in the southwest pacific ocean during the last glacial period and deglaciation. Nature 405, 555-559.
Solomon, S., Qin, D., Manning, M., Chen, Z., Marquis, M. and coauthors. 2007. Climate change 2007: The physical science basis., Contribution of Working Group I to the Fourth Assessment Report of the Intergovernmental Panel on Climate Change, Cambridge University Press, Cambridge, United Kingdom and New York, NY, USA.

Strassmann, K., Joos, F. and Fischer, G. 2008. Simulating effects of land use changes on carbon fluxes: past contributions to atmospheric $\mathrm{CO}_{2}$ increases and future commitments due to losses of terrestrial sink capacity. Tellus 60B, 583-603.

Trudinger, C., Enting, I., Francey, R. and Etheridge, D. 1999. Long-term variability in the global carbon cycle inferred from a high precision $\mathrm{CO}_{2}$ and $\delta^{13} C$ ice core record. Tellus 51B, 233-248.

Trudinger, C., Enting, I., Rayner, P. and Francey, R. 2002. Kalman filter analysis of ice core data 2.: double deconvolution of $\mathrm{CO}_{2}$ and $\delta^{13} \mathrm{C}$ measurements. J. Geophys. Res. 67, 174-180.

Trudinger, C., Enting, I., Etheridge, D., Francey, R. and Rayner, P. 2005. The carbon cycle over the past 1000 years inferred from the inversion of ice core data. In: A History of Atmospheric $\mathrm{CO}_{2}$ and Its Effects on Plants, Animals and Ecosystems (ed. J. Ehleringer), Ecological Studies, Volume 177,Springer, New York, NY, 329-349.

Wanner, H., Beer, J., Bütikofer, J., Crowley, T., Cubasch, U. and coauthors. 2008. Mid- to late holocene climate change: an overview. Quater. Sci. Rev. 27, 1791-1828.

\section{Supporting information}

Additional Supporting Information may be found in the online version of this article:

Appendix S1. The bookkeeping model.

Appendix S2. The process model.

Appendix S3. "Certainty" of past $\mathrm{CO}_{2}$.

Please note: Wiley-Blackwell are not responsible for the content or functionality of any supporting materials supplied by the authors. Any queries (other than missing material) should be directed to the corresponding author for the article. 